\title{
El arte como posibilidad de mediación en los conflictos: escenarios, prácticas y visibilidad desde las experiencias en el Huila
}

Art as a possibility of mediation in conflict: scenarios, practices and visibility from the experiences in the Huila

Arte como possibilidade de mediação em conflitos: cenários, práticas e visibilidade das experiências do Huila

Jaime Ruiz Solórzano

Doctorado en estudios sociales Docente Universidad Surcolombiana jairuso@usco.edu.co

\section{Resumen:}

El presente texto reflexivo tiene la intención de poner en común, las maneras como las prácticas artísticas generadas por un exestudiante, dos estudiantes y una docente del Programa de Educación Artística han iniciado sus aportes a la mediación del conflicto interno colombiano y guatemalteco. El escrito se encuentra organizado en cinco partes: 1. La necesidad de la mediación en el conflicto armado colombiano. 2. En la resolución de los conflictos ¿Para qué sirve el arte? 3. La posibilidad de mediación de las prácticas artísticas en el exordio de la solución del conflicto. 4. Trayectorias de las prácticas artísticas como mediación en los conflictos. 5. Cuatro prácticas artísticas como experiencias de potencial conciliatorio en el conflicto colombiano y guatemalteco.

Palabras claves: Conflicto, mediación, prácticas artísticas.

\section{Summary:}

This reflective text intends to put in common, the ways in which the artistic practices generated by a former student, two current students and a teacher of the Artistic Education Program have begun their contributions 
El arte como posibilidad de mediación en los conflictos: escenarios, prácticas y visibilidad desde las experiencias en el Huila

to the mediation of the Colombian and Guatemalan internal conflict. The document is organized in five parts: 1 . The need for mediation in the Colombian armed conflict. 2. In the resolution of conflicts, What is art for? 3 . The possibility of mediation regarding artistic practices in the exordium of the conflict solution. 4. Trajectories of artistic practices as mediation in conflicts. 5. Four artistic practices as experiences of conciliatory potential in the Colombian and Guatemalan conflicts.

Keywords: Conflict, mediation, artistic practices.

\section{Resumo:}

O presente texto reflexivo tem a intenção de colocar em comum, as formas como as práticas artísticas geradas por um ex-aluno, dois alunos e um professor do Programa de Educação Artística iniciaram suas contribuições para a mediação do conflito interno colombiano e guatemalteco. $\mathrm{O}$ documento está organizado em cinco partes: 1 . A necessidade de mediação no conflito armado colombiano. 2. Na resolução de conflitos O que é arte? 3. A possibilidade de mediação de práticas artísticas no exórdio da solução do conflito. 4. Trajetórias de práticas artísticas como mediação em conflitos. 5. Quatro práticas artísticas como experiências de potencial conciliador nos conflitos colombianos e guatemaltecos.

Palavras-chave: Conflito, mediação, práticas artísticas.

La necesidad de la mediación en el conflicto armado colombiano

Según los especialistas en teoría de los conflictos, estos son consubstanciales a la naturaleza humana. Para el marxismo es el "motor de la historia", al considerar que

los conflictos son necesarios; constituyen el motor del cambio social, y vienen generados por la incompatibilidad de intereses entre grupos humanos. Pero el conflicto deja de ser funcional en algunas circunstancias excepcionales, y puede transformase en una disfunción básica que obstruya la adecuada marcha del sistema, e incluso sea capaz de destruirlo (González Calleja, 2002, p. 109).

Tal es el caso de Colombia cuando después de más de 68 años de guerra interna y de violencia exacerbada, comienzo a aceptarse como el estado patológicamente trágico de nuestra sociedad, incapaz de resolver las contradicciones de manera autónoma; que aparte de muerte, miseria y destrucción para el pueblo, solo ha contribuido a fortalecer el capital 
y el poder de los grupos económicos y políticos.

Probablemente no desaparecerá del todo, dada la megalomaníaca obsesión por el poder y la acumulación de riqueza, que persiste entre los dueños de la guerra, junto a los partidarios que los rodean. Porque lo que opera desde los distintos actores que la promueven y la afirman, es la asunción soterrada del moldeamiento fascista; junto al uso de las armas, el terror focalizado y sus depredadoras acciones; propias de la Necropolítica (Mbembe, 2011), y la Cleptocracia (Vásquez Roca, 2016), como únicas salidas ante las contradicciones sociales.

Hoy, afortunadamente han soplado vientos favorables que tienden a disiparla. Es precisamente, en este interregno de la barbarie, que asistimos a "iluminaciones" tangibles, como diría Walter Benjamin; al presentir que la actual coyuntura articulará, junto a la concitación de voluntades, un "motor de cambio" alternativo, tanto para las personas afectadas por la violencia como para los contextos sociales y los territorios donde habitan.

De otra parte, entendemos la mediación como un proceso a través del cual un tercero interviene, gestionando un espacio neutral y facilitando el diálogo, con el fin de propiciar la solución entre las partes que afrontan un conflicto. Actualmente los mediadores cobran mayor relevancia, dada la urgencia de intervenir el conflicto, según explican Wills y Martínez-Villalba (2003):

Los terceros actores se volvieron centrales en los procesos de resolución y sus roles se multiplicaron. En este contexto, cada vez más actores nacionales e internacionales se involucran en los procesos de pacificación. La responsabilidad ya no es sólo de los Estados; ahora es compartida por toda la gama de esferas que interactúan en el nuevo escenario (...) Cada agente desde la posición que ocupa, puede aportar en dichos procesos, bien sea mediante la provisión de información o recursos, la facilitación de diálogos entre los actores contendientes, la promoción de acuerdos, o la decisión de soluciones (p. 1-2).

Desde el ámbito de las ciencias sociales se han establecido las metodologías y las estrategias, que implican las condiciones éticas o los principios, las reglas de participación, y las herramientas de resolución, orientadas a implementar las mediaciones.

En tales abordajes se suele tener en cuenta el contexto y las prácticas culturales de los grupos sociales (comprensión socio- 
El arte como posibilidad de mediación en los conflictos: escenarios, prácticas y visibilidad desde las experiencias en el Huila

cultural); las personas involucradas (aspectos psicológicos-emocionales), la problemática (componentes específicos del conflicto), el proceso del problema (maneras de resolución implementadas).

Generalmente toda mediación se encamina a restablecer el respeto, motivar la tolerancia, neutralizar las acciones legales obstructoras; identificar alternativas, construir acuerdos, y pactar compromisos; propiciando un clima de diálogo cara a cara, donde tienda a prevalecer la igualdad y la responsabilidad, el cese de hostilidades y la no repetición de acciones violentas; el respeto de los Derechos Humanos y de los ciudadanos.

Mientras los objetivos de las mediaciones se encaminan a "facilitar el diálogo, aclarar malentendidos, propiciar encuentros, proponer soluciones alternativas, $\quad$ y/o cambiar percepciones contradictorias e irreconciliables por otras que faciliten acuerdos" (Wills y Martínez-Villalba, 2003, p. 3).

Para ello es indispensable restablecer la confianza, reconstruir el entramado de las relaciones sociales; otear el horizonte de posibilidades, con el propósito de identificar fines comunes; y hacer la coexistencia posible, en un proyecto de sociedad más justo e incluyente.
En estas dinámicas, se hace pertinente el accionar de las diversas mediaciones, incluyendo las políticas, las económicas, las terapéuticas, las sociales, las culturales y las artísticas.

\section{En la resolución de los conflictos ¿Para qué sirve el arte?}

Generalmente se considera que el arte es una práctica suntuaria, exotérica e inútil, que solamente en sociedades con gran capital económico, cultural y simbólico; es decir, las del mundo euronorteamericano, a lo sumo, contribuye a enriquecer la sensibilidad, el acervo cultural, y los recursos económicos de quienes dinamizan su especulación.

La gran mayoría reconoce en el arte uno de los medios que la ha posibilitado a la humanidad existir, desde los albores prehistóricos hasta el tiempo actual. Es decir, que las prácticas artísticas, a través del tiempo, han servido como una mediación entre las necesidades expresivas de los individuos y los avances de las sociedades; contribuyendo en los procesos de comprensión, relación, y creatividad humana. Al respecto explica Pilan (2010):

De esta forma, es constantemente necesaria la construcción de nuevos medios para a la sobrevivencia. Es, como en un círculo vicioso, desde los tiempos en que se 
produjo el conocimiento, los hombres usan el arte en la búsqueda para comprenderse a sí mismo y el mundo, insertarse en él, estableciendo moldes propios de seguridad y libertad básica (p. 157).

En nuestros contextos, se suele desconocer toda la trayectoria y los aportes del arte en el devenir de la cultura humana, en ocasiones originado por la intelligensia institucional, se considera que el arte y la educación artística es un saber superfluo; en la medida que poco o nada resuelve en la vida práctica, o para afrontar situaciones de la realidad. En últimas, determinan su inviabilidad arguyendo que solamente se debe formar para promover la vocación económica regional.

En contravía Chalmers retrotrae esta inquietud $y$ replantea la pregunta esencial: “¿Para qué sirve el arte?” (2003, p. 67). Su respuesta es argumentada, teniendo como referencia tres perspectivas importantes.

La primera perspectiva, enunciada por Ellen Dissanayake. La autora afirma que el arte ofrece cuatro posibilidades: A) El arte se encuentra directamente conectado con el "mundo natural", por lo cual lo "refleja" y le sirve de "caja de resonancia". En este sentido el arte es terapéutico, porque integra poderosos sentimientos contradictorios y perturbadores; prevé la manera de evitar el tedio y permite la participación temporal en un mundo alternativo más deseable; a su vez, ofrece ilusiones consoladoras; promueve la catarsis de emociones perturbadoras (Chalmers, 2003, p. 76).

B) También el arte tiene la capacidad de "restablecer temporalmente la trascendencia, el valor $y$ la integridad de la sensualidad y el poder emocional de las cosas, en contraposición con la indiferencia general de nuestra vida práctica rutinaria y sin horizontes" (Dissanayake citada por Chalmers, 2003, p. 76).

C) El arte

ejerce una función de deshabituación, en el sentido que nuestra respuesta al arte puede optar por formas inusuales, no habituales. El arte ofrece una sensación de sentido $o$ trascendencia $o$ intensidad a la vida humana, que no puede obtenerse por ningún otro camino (Chalmers, 2003, p. 77).

D) "El arte es un medio de ponernos en contacto con los demás en busca de solidaridad; es un medio de comunión y a la vez de comunicación" (Chalmers, 2003, p. 77). A esta perspectiva, Chalmers (2003) añade que el arte además "ejercita y entrena nuestra percepción de la realidad... [al] 
El arte como posibilidad de mediación en los conflictos: escenarios, prácticas y visibilidad desde las experiencias en el Huila

prepararnos para las embestidas de la vida, al fijar nuestra atención en cosas que deberían preocuparnos, como miembros de esa cultura" (p. 77).

Segunda perspectiva, referenciada en E. Louis Lankford. Este educador argumenta que el arte es valorado por varias razones, entre ellas por

la experiencia placentera que proporciona, su valor económico, su impacto emocional, su utilidad desde el punto de vista de la crítica social y su potencial influencia política". Igualmente se reconoce su valor por la capacidad que tiene de embellecer, sorprender, inspirar, estimular la imaginación, informar, contar historias y dejar constancia de la historia; por la clarividencia que demuestra acerca de la condición humana; por sus logros técnicos; por su interpretación del espíritu de culturas particulares (Chalmers, 2003, p. 77).

Tercera perspectiva, basada en June King McFee, quien asigna al arte "seis funciones primarias", las cuales influyen "en las experiencias de personas de todas las culturas" (Chalmer, 2003, p. 77).

1) "El arte objetiva", ya que "a través de él, valores, emociones, ideas, creencias y supersticiones pertenecientes básicamente al mundo subjetivo se vuelven más sensorialmente tangibles, hasta el punto de que pueden ser vistos y sentidos" (Chalmers, 2003, p. 77).

2) "El arte realza y se utiliza para enriquecer la celebración y el ritual en los acontecimientos humanos" (Chalmers, 2003, p. 77).

3) "El arte también discrimina y organiza; confirma rangos y roles diciéndole a la gente quiénes son los otros" (Chalmers, 2003, p. 77).

4) "Como comunicación, el arte se utiliza para consignar, transmitir y generar significados, cualidades e ideas" (Chalmers, 2003, p. 80).

5) "El arte tiene un rol en la continuidad y el cambio culturales. Ayuda a estabilizar las culturas al perpetuar tanto las convicciones de realidad de los miembros de una cultura como las identidades y los logros de individuos y de grupos" (Chalmers, 2003, p. 80)

6) Contribuye a generar " $\mathrm{el}$ cambio cultural, al identificar los problemas, satirizar determinadas condiciones y pintar visiones alternativas, el arte también puede desestabilizar las culturas" (Chalmers, 2003, p. 80).

De acuerdo con los anteriores enunciados, el arte juega un papel esencial en la formación integral de los individuos, en la medida que abre sensibilidades $y$ sensorialidades, posibilidades 
creativas y expresivas, valoraciones del sentido en el mundo de la vida, y motiva la asunción de la identidad cultural.

Similar trascendencia ejerce en las sociedades, considerando que son esenciales los aportes del arte para la conservación de la memoria, propiciar la crítica y sus efectos políticos, contribuir a la ampliación de los nexos sociales y las interacciones comunicativas; sobre todo, al mediar la participación en las dinámicas de la continuidad y el cambio sociocultural. Similares papeles son factibles de propiciar en la mediación del conflicto.

\section{La posibilidad de mediación de las prácticas artísticas en el exordio de la solución del conflicto}

Una alternativa procesual en los conflictos, puede constituirla los procesos mediadores a través de las prácticas artísticas. Se ha identificado que las mediaciones en el mundo del arte, se producen donde se involucran: los artistas, las obras, y los dispositivos de difusión (espacios expositivos y medios infográficos).

Aunque una de las condiciones de la mediación artística es que "se produce, aplica, reproduce y extiende dentro de campos muy diversos que están siempre en relación directa con el contenido y los parámetros del arte contemporáneo más reciente"
(Rodrigo-Montero, 2015, p. 376). Afirma Rodrigo-Montero (2015) que las mediaciones en el mundo del arte poseen tres tipos:

Primero. Mediación como modelos educativos. Aplicada como proceso de Ez-Az, inherente a la educación artística contemporánea. Aquí el elemento "mediador" es la estética o la educación estética; ésta con alcances más amplios al conferir mayor protagonismo al participante, donde el proceso opera como espejo y medio de auto-experiencia y autoformación. Es lo que se define como "educación en museos o en las galerías", "en exposiciones o centros de arte". Se encuentra "basada en la nueva museología y la museología crítica" (2015, p. 377).

Segundo. Mediación como actividad curatorial. Propia de proyectos organizados de manera horizontal y con estrategias de difusión interdisciplinarias, desde la museología crítica. También de proyectos curatoriales colaborativos o pedagógicos; encaminados a favorecer las participaciones, los mutuos aprendizajes, y la visibilización de grupos generalmente marginados. En este tipo de proyectos es muy importante el fomento de la comunicación, las interacciones e intercambio de saberes. Estos proyectos y el montaje de las exposiciones corresponden a la llamada "curaduría crítica"; 
El arte como posibilidad de mediación en los conflictos: escenarios, prácticas y visibilidad desde las experiencias en el Huila

implicando componentes de gestión, negociación, políticos, crítica institucional y de la actividad curatorial (2015, p. 377).

Tercero. Mediación como campo de expansión. Retomando elementos de las dos anteriores, esta mediación

se genera dentro y fuera del sistema del arte.... El arte contemporáneo como proceso cultural se desplaza, emplaza, y se mezcla con otras prácticas culturales.... La dimensión expansiva del término "arte" hacia otros terrenos... adquiere para sí misma cada vez un mayor rango de estructuras mediadoras produciendo comunicaciones imposibles, impredecibles o latentes en potencia.... En este punto la consideración de la mediación artística se nutre de elementos ajenos al mundo del arte que finalmente son incluidos en el pensamiento estético, generando espacios de hibridación y zonas de contacto constantes (2015, p. 377-378).

Debemos precisar que tales iniciativas solo se aplican en la cuadricefalia del país, pero poco se cumplen en nuestros contextos, dada la diversidad étnica que asiste a la sincronía de varias formas de vivir, en el llamado fenómeno de la "simultaneidad cultural". Esto significa que contamos con grupos humanos que recientemente superaron la trashumancia (comunidad Embera-Chami de Orito- Tarqui), comunidades tradicionales indígenas y afrocolombianas, colectividades campesinas, sociedades urbanitas, y personas que habitan en los circuitos internacionales.

Estas diferencias culturales al ser abordadas en las prácticas artísticas tienen resonancias y correspondencias formales y conceptuales con lo que se alude en las imágenes, en cuanto a si las figuraciones son interpretadas, representadas o presentadas; en cuanto se puedan inscribir en el arte moderno o contemporáneo, en las estéticas y poéticas tradicionales, en las estéticas pragmáticas o prosaicas; en cuanto son objetivizadas con diversas Figuraciones y Discursos (Ruiz, 2017).

No obstante, identificamos que la mediación de las prácticas artísticas, aunque incluye los distintos subsistemas del mundo del arte, interviene en la realidad del conflicto; donde lo que resulta valioso y significativo son los mismos procesos de mediación, cuando se generan las dinámicas del sentir, pensar y hacer, como resultado de la interacción entre las mediaciones, arriba enunciados y las comunidades específicas.

Con ello la calidad de los productos finales resultantes de los procesos de mediación pueden 
pasar a un segundo plano, quedándose relegada su exhibición a los sitios de producción. En razón a que suelen ser considerados inapropiados para ser montados en exposiciones convencionales, subvalorados a nivel de la institución artística, y por fuera del coleccionismo y su mercantilización, cuando se posee una mentalidad apegada a los dictamines pautados del arte contemporáneo. Lo importante, como recomendaba Dewey (2008), es: "recobrar la continuidad de la experiencia estética con los procesos normales de la vida" ( $p$. 11).

Desde otro ángulo tal mediación puede incluir otros trabajadores de las ciencias sociales y del ámbito de la cultura, buscando sustraer a las comunidades de los programas y estrategias de cooptación partidistas y propiciar su integración a políticas sociales más abarcadoras. $\mathrm{Al}$ respecto dicen Carnacea y Lozano (2011):

No se trata a mi entender de poner sólo el arte y la creatividad al servicio de lo social, sino de articular un proyecto más amplio que ponga en contacto a educadores, artistas, sociólogos terapeutas y otros trabajadores socioculturales con una política cultural integral que desafíe las frecuentes inmersiones partidistas del espacio de la producción y la lucha por el poder. (p. 12)

\section{Trayectorias de las prácticas artísticas como mediación en los conflictos}

Consideramos que la genealogía de las prácticas artísticas correlacionadas con comunidades específicas frente a los conflictos, datan de las posturas del Arte político que se crea para difundir los esquemas ideológicos y conlleva a una eventual solución de la problemática que representan las creaciones. Se trata de obras que son producto de las militancias partidistas $\mathrm{o}$ promovidas por organizaciones específicas. En concreto, se trata de los proyectos de denuncia y resistencia de las décadas del 60 y el 70; en este caso, la política de representación tiene prioridad sobre la representación de la política.

Aquí se encuentran los movimientos o estilos de arte que promocionan la difusión de ideales políticos a través de estrategias masivas: 1) La producción de creaciones visuales que se instalan y circulan en espacios públicos (murales, afiches, chapolas, revistas, catálogos, almanaques, videos, acciones o instalaciones efímeras); 2) La ejecución de proyectos en instituciones o espacios urbanos de sectores populares y en medios de comunicación alternos 
El arte como posibilidad de mediación en los conflictos: escenarios, prácticas y visibilidad desde las experiencias en el Huila

(sindicatos, plazas, parques, instituciones educativas, periódicos populares); 3) La gestión de programas de enseñanza y talleres de creación artística que beneficien al pueblo.

Las anteriores prácticas se encaminan a establecer una correlación, donde el aspecto particular de un acontecimiento se destaca respecto a otros. El hecho que muestra se centra en las personas o grupos que están comprometidos en cambiar la situación en la que se encuentran; aquí la política general es explícita y puede tener un efecto inspirador positivo; además, son significativas en la medida que confieren trascendencia o heroísmo a los grupos comprometidos.

De manera similar, el Arte Activista, vigente desde la década de los años 80 hasta tiempos actuales, surge como una respuesta contra las iniquidades que afectaban las minorías sociales y los desequilibrios económicos y sociales mundiales; surgidas como repercusiones de la era neoconservadora y neoliberal.

En estas circunstancias eran palpables las luchas generadas por "la homosexualidad, el sida, las reivindicaciones feministas, la integración racial, el derecho al aborto, las cuestiones relativas al Tercer Mundo, el apartheíd" (Guasch, 2007, p. 476). En efecto, comprendemos que el Arte activista posee propósitos claramente críticos y de resistencia.

En esta corriente artística se aunaron tres tendencias: una, donde el significado y valor del arte radica en el contexto social y territorial. Otra, en que la participación de los públicos en los procesos creativos era ineludible. La última, donde las "obras de arte" reconocidas por el Mainstream pasaron a un plano de prestigio hegemónico, valioso solo para el mercado y como capital simbólico. $\mathrm{Al}$ respecto dice Guasch (2007):

De productor de objetos de arte, el artista pasó a "manipulador" social de signos artísticos, y, a su vez, el espectador dejó el papel de pasivo contemplador estético y consumidor del espectáculo artístico, para convertirse en lector activo de mensajes. El arte se transformó en un signo social estrechamente ligado a otros signos en una estructura de sistemas productores de valor, poder $\mathrm{y}$ prestigio $(\mathrm{p}$. 476).

También algunas tendencias del arte de los años 90 se convirtieron en medios para facilitar la observación, la alteración del pensamiento y la acción real de los públicos, donde se pusieron a prueba experiencias anteriores. Ante lo cual Foster (2001) argumenta: “Asistimos a un giro hacia lo real, por un lado, y a un giro hacia el referente por el otro. $\mathrm{Y}$ estos giros comportaron 
diferentes retornos, diferentes genealogías del arte y la teoría” (p. 126). Más adelante explica que el retorno opera como un "deslizamiento" de la imagen a la percepción de presentaciones tangibles. Ante ello dice: "Este deslizamiento en la concepción de la realidad como efecto de la representación, a lo real en cuanto traumático- puede ser definitivo en el arte contemporáneo" (p. 150).

Tal realidad presenta tres vías de las prácticas artísticas: la primera, relacionada con el Hiperrealismo y el Apropiacionismo objetual. La segunda, entroncada con el Arte abyecto y la presencia de cuerpos violentados (Foster, 2001, p. 153156). La tercera, e importante para el tema que abordamos, el artista asume roles del Etnógrafo: aquí el creador elige una comunidad, se involucra en su cultura, propone un proyecto basado en problemas sentidos, y los co-gestiona con diversos públicos (Foster, 2001, p. 206). Respecto a esta tercera ruta de trabajo, Foster (2001) advierte:

Este modo horizontal de trabajar demanda que artistas y críticos conozcan no sólo la estructura de cada cultura lo bastante bien como para mapearla, sino también su historia como para narrarla. Así, si uno desea trabajar sobre el sida, debe entender no sólo el aliento discursivo, sino también la profundidad histórica de las representaciones del sida (p. 206)

De acuerdo con Suzanne Lacy (1994), existen cuatro funciones "no exclusivas" para los artistas que se dedican a la interacción social, factibles de hacer extensivas a la mediación del arte en el conflicto, conllevando a que las prácticas artísticas oscilen entre lo "subjetivo y lo público".

Estos roles corresponden al artista como experimentador, reportero, analista, y activista: 1) Subjetividad y Empatía: Artista como experimentador. En esta función, los artistas se incorporan en el territorio del "otro" y luego informan sobre las observaciones hechas de esta experiencia. 2) Información Revelada: Artista como Reportero: El artista recoger información, luego elabora los "informes de los resultados", y los dispone ante el público en general. Como existe una "selección consciente" de la información, el artista tiene como propósito "persuadir" y aleccionar al público. 3) Situaciones y Soluciones: Artista como Analista: Los artistas se interesan menos en las posibilidades visuales y más en las construcciones de su práctica en un contexto específico 4) Construcción de Consenso: Artista como activista: donde la práctica artística se realiza en contextos y situaciones reales, haciendo posible que el público se convierte en un participante activo. 
El arte como posibilidad de mediación en los conflictos: escenarios, prácticas y visibilidad desde las experiencias en el Huila

\section{Cuatro prácticas artísticas como experiencias de potencial conciliatorio en el conflicto colombiano y guatemalteco}

En nuestro Departamento del Huila es de trascendencia nacional e internacional el proyecto gestionado por el gestor cultural Rodríguez (2014), con el título de Mil Colores para mi pueblo. Rodríguez (2014) realizó una intervención en Vegalarga-Neiva, población del Huila que había padecido más de veinticinco tomas guerrilleras en el lapso de una década y posteriormente en El Paraíso-Algeciras. En ambos proyectos las comunidades participaron activamente.

La iniciativa realizada en el Municipio de Algeciras, permitió restablecer los lazos rotos de las comunidades de Paraíso Viejo y Paraíso Nuevo, que habían sido divididos por ancestrales disputas por el territorio e intereses vecinales; además de ser afectados ambos sectores por los hechos violentos de la guerra.

Como resultado final, los miembros de la comunidad repararon las fachadas de sus residencias, las pintaron con colores contrastantes; instalaron materas-esculturas, creadas con objetos reutilizados; se reencontraron y construyeron diálogos de futuro. Al respecto, dijo el Diario La Nación (2014):
En la jornada, unas 350 fachadas de viviendas fueron pintadas en un trabajo orientado por 11 artistas de la Fundación, que permanecieron por más de siete días capacitando en temas de estética, reconocimiento, identidad, teoría del color, entre otros, a los habitantes de este sector, para que ellos mismos realizaran el trabajo de pintura en sus casas... Las viviendas además de ser pintadas están acompañadas de un trabajo de resignificación de objetos que han dado muerte como cilindros bombas, granadas, entre otros materiales bélicos, al igual que reciclables. Igualmente, se realizaron murales y grafitis que hacen que la población se embellezca (p. 1).

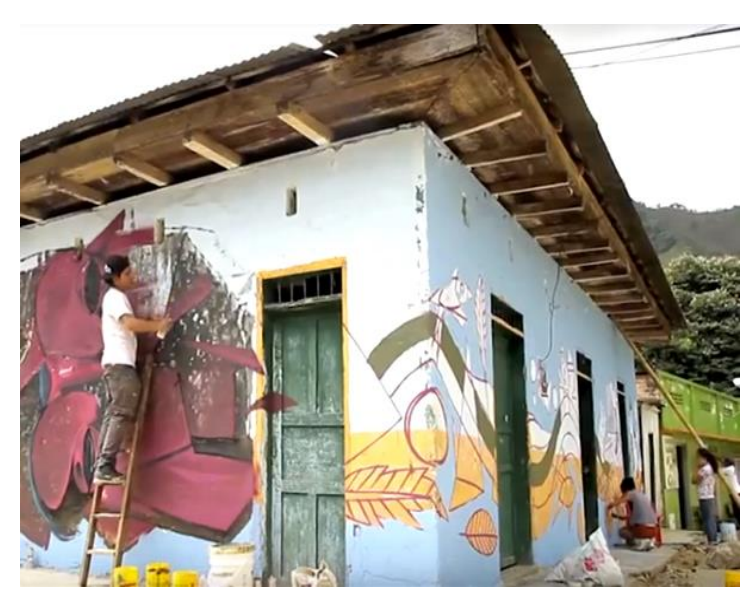

Figura 1 "Mil colores para mi pueblo". Detalle video Youtube. Casa intervenida, Vegalarga-Huila

Fuente: Cartelurbano (2014). Mil colores para mi pueblo-Vegalarga, 28 de Febrero.

Recuperada de http://cartelurbano.com/historias/milcolores-para-mi-pueblo 


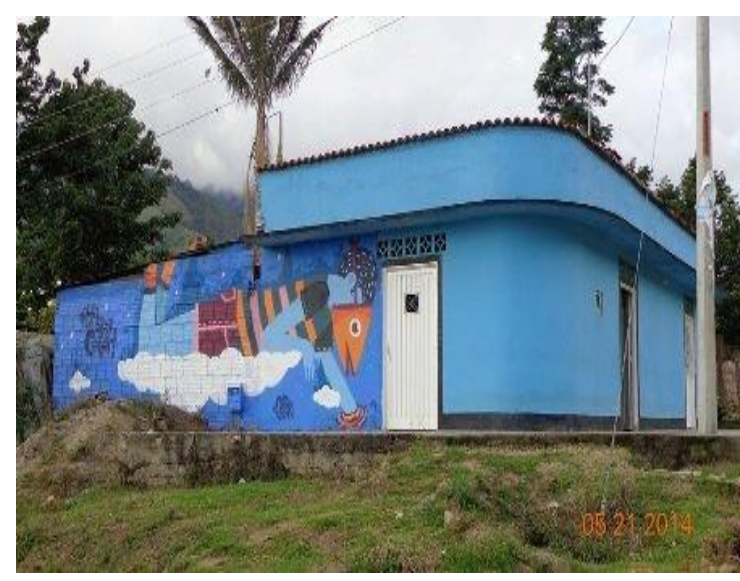

Figura 2 "Unas 350 fachadas de las casas de Paraíso fueron pintadas de colores alegres"

Fuente: La Nación (2014) "Paraíso tiene mil colores". Neiva, 29 de Mayo. Recuperada de http://www.lanacion.com.co/2014/05/29 /paraiso-tiene-mil-colores/

El mismo Rodríguez (2017) trabajó el proyecto denominado "Memorias a Color-Una puerta hacia la reconciliación". En esta ocasión se trató de una apuesta artísticas encaminada a crear un diálogo reflexivo entre víctimas y victimarios del conflicto colombiano con el fin de buscar la reconstrucción del tejido social. Es una "Reparación Simbólica" por parte de los victimarios y de "Perdón" por parte de las víctimas. En teoría "Memorias a Color" sería un "catalizador del dolor que ha causado la guerra en la voz de quienes la vivieron, una garantía de no repetición y una reconciliación de la Colombia profunda".

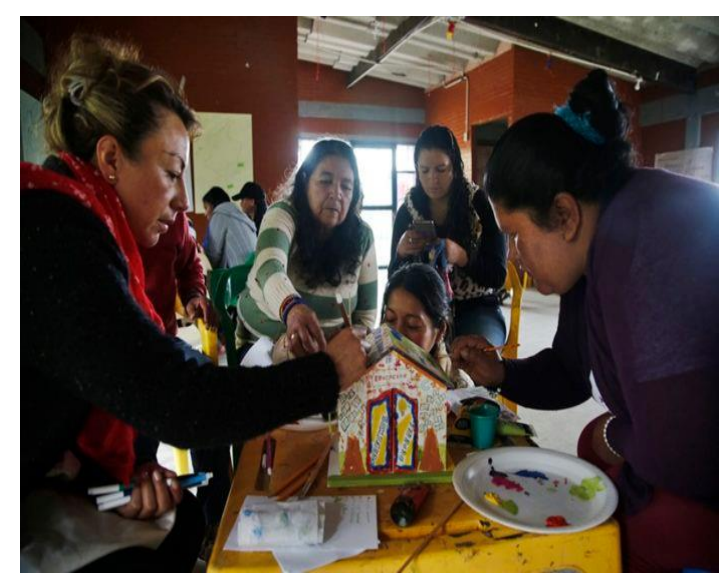

Figura 3 "Memorias a color". Las piezas del proyecto fueron elaboradas por desmovilizados y luego pintadas por víctimas. Foto: Archivo particular

Fuente: El Filtro.com (2017). Memorias a Color-Una puerta hacia la reconciliación. Bogotá, 8 de febrero. Recuperada de http://www.elfiltro.co/memorias-a-color/

El proyecto consistía en que luego de una intervención psicológica y pedagógica las víctimas del conflicto armado representaran sus vivencias y el dolor causado, en unas casas de unos $25 \mathrm{~cm}^{3}$, fabricadas en MDF. Para tal efecto algunos combatientes desmovilizados de las FARC, el ELN y de Grupos Paramilitares crearon unas 300 casas, después de ser capacitados por el Servicio Nacional de Aprendizaje-SENA. La iniciativa buscaba que, a través de las actividades artísticas, se crearan espacios de encuentro que posibilitaran los procesos de reparación y reconciliación en las comunidades afectadas por la violencia política. 
El arte como posibilidad de mediación en los conflictos: escenarios, prácticas y visibilidad desde las experiencias en el Huila

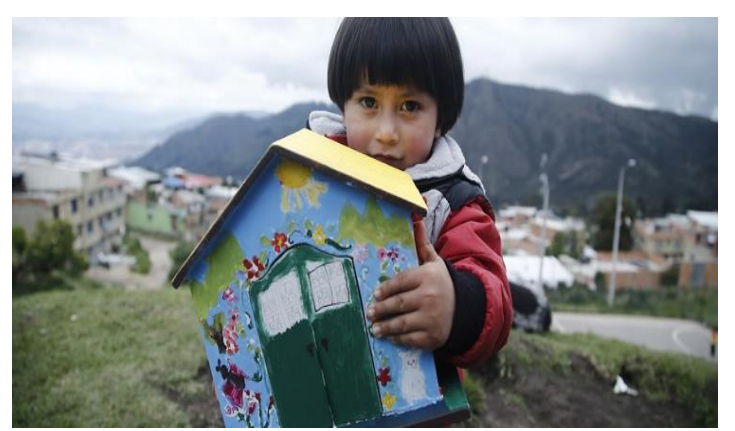

Figura 4 "Memorias a color". Niño sobreviviente proyecto "Memorias a color"

Fuente: Archivo fotográfico de Edwin Rodríguez. 2017.

El montaje fue realizado con 15 piezas pintadas por las víctimas o sobrevivientes, y fue complementado con la participación de 30 artistas que intervinieron las casas; entre estos se encontraban Pedro Ruiz, Luis Carlos Cifuentes, Felipe Bedoya, Beatriz González, Germán Tessarolo, Oscar Álvarez. Es notoria la mayor cantidad de piezas de los artistas que las de las victimas/sobrevivientes; como si a los primeros se le confiriera mayor trascendencia.

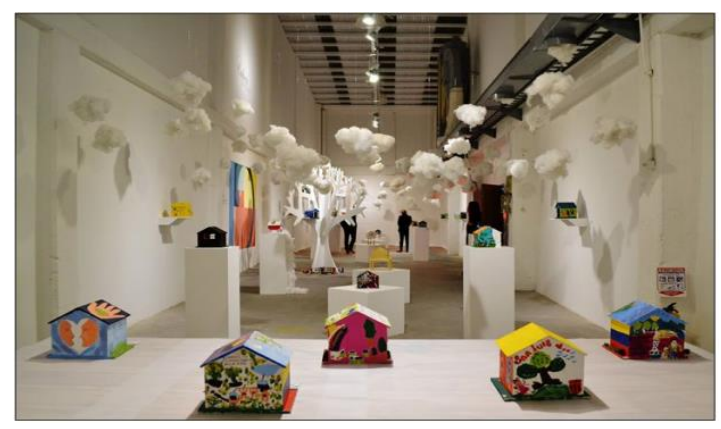

Figura 5 "Memorias a Color". Vista del montaje. Galería Herencia Verde. 2017.

(Espacio de Pinturas Tito Pabón, Bogotá Cra. 27 No. 78-44)
Fuente: Archivo Fotográfico de Edwin Rodríguez. 2017.

Las obras además incluían textos escritos donde se expresaban mensajes como "mejor pluma que plomo" o "anhelamos horizontes de reconciliación" (El Tiempo, 2017). La proyección del proyecto fue extenderlo al Huila, Caquetá, Cauca, Putumayo, Antioquia, Bolívar, Cundinamarca, Chocó y Arauca. Además, exponerlo en el ámbito internacional.

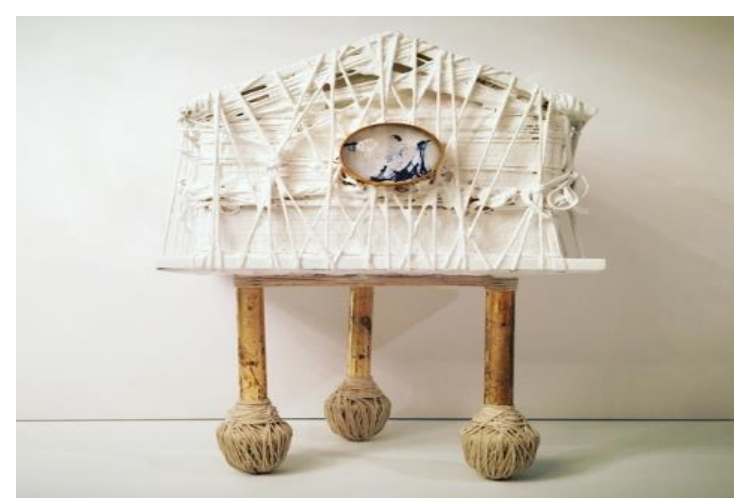

Figura 6 "Memorias a Color". Detalles de la inauguración. Galería Herencia Verde. 2017.

Fuente: El Tiempo (2017). Víctimas y victimarios se reunieron para "pintar" la paz. Bogotá, 18 de Febrero Recuperada de http://www.eltiempo.com/politica/proces o-de-paz/victimas-y-victimarios-sereunieron-para-pintar-la-paz-60452

En el Departamento del Huila durante el año 2017 el proceso de creación se adelantó con las víctimas del conflicto armado en los municipios de Neiva, Garzón, Pitalito, La Plata y Algeciras. El montaje general fue realizado en el Museo de Arte Contemporáneo 
del Huila-MACH con registros fotográficos de las actividades realizas, las obras de las víctimas, y de creadores como Pablo Mosquera con "Alma infinita", Javier Chinchilla con "Desplomada y desplumada", Miguel Darío Polanía con "Tumbar puertas, abrir ventanas", Francy Elena Conde con "Que florezca la paz", y los estudiantes del Programa de Educación Artística de la Universidad Surcolombiana: Juan Camilo Torres Leyton con "Amnesia", y Valentina García con "Chamiza".

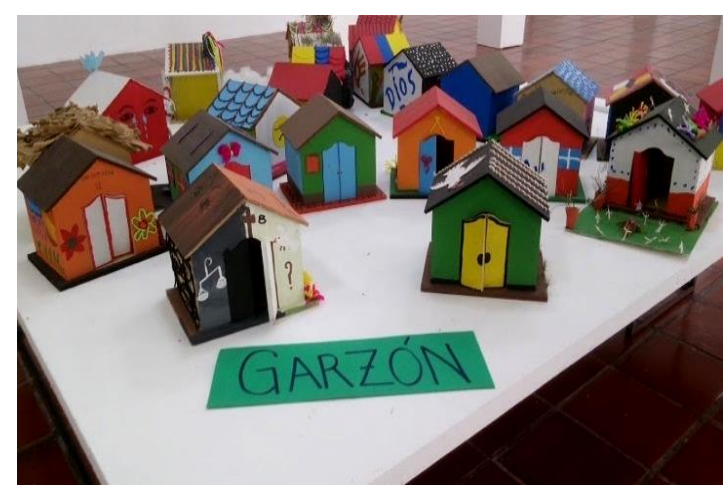

Figura 7 "Memorias a Color". Piezas realizadas por las víctimas del Municipio de Garzón. Museo de Arte Contemporáneo del Huila MACH, 2017.

Fuente: Fotografía de Juan Camilo Torres Leyton. 2017.

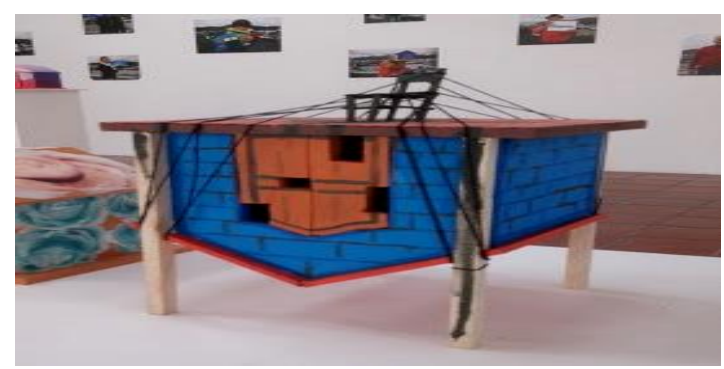

Figura 8 "Amnesia”. Juan Camilo Torres Leyton. Acrílico sobre MDF. Museo de Arte Contemporáneo del Huila MACH, 2017.
Fuente: Fotografía de Juan Camilo Torres Leyton. 2017.

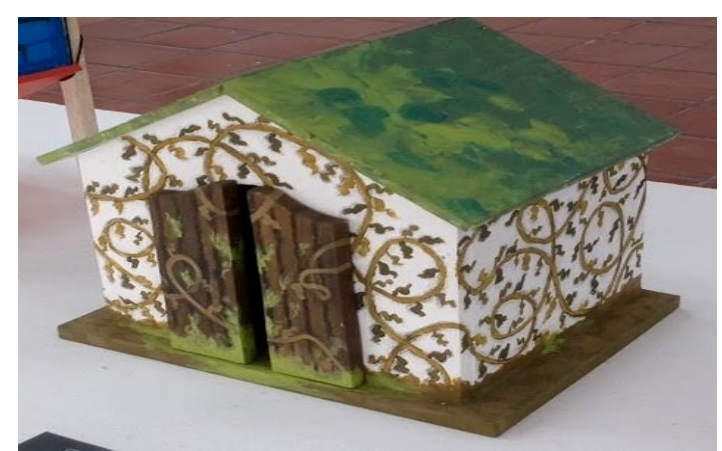

Figura 9 "Chamiza". Valentina García T. Acrílico y vinilo sobre MDF. Museo de Arte Contemporáneo del Huila MACH, 2017.

Fuente: Fotografía de Juan Camilo Torres Leyton. 2017.

Bastante significativa como proceso de interacción con participantes del conflicto, es la experiencia que realizó en un período vacacional del semestre anterior el "Colectivo Artístico "REVOLART" (Revolución Artística)” (2017), con la participación de los jóvenes Arlex Mauricio Arcila y Anthony Ordoñez, estudiantes del Programa de Educación Artística, quienes corrieron la aventura de participar en procesos de formación y creación en dos Zonas Veredales de Concentración de excombatientes, en los departamentos Meta y Guaviare, ubicados en el oriente colombiano. Al respecto explica el estudiante:

El colectivo artístico
"REVOLART"
Artística) conformado por 4
artistas colombianos, entre


El arte como posibilidad de mediación en los conflictos: escenarios, prácticas y visibilidad desde las experiencias en el Huila

ellos de visuales danza, música y artes escénicas; quienes quisieron por iniciativa propia aportar un granito de arena al Proceso de Paz por el que pasa Colombia y haciendo lo que más les gusta que es el arte, orientaron varios talleres de música, teatro, danza y pintura en las Zonas Veredales Transitorias de Normalización (ZVTN), a los excombatientes de las Fuerzas Armadas Revolucionarias de Colombia (FARC). Tuvimos la oportunidad de internarnos en dos Zonas Veredales: la primera, la Zona Verdal del Yarí, Macarena, Meta, denominada Urías Rondón; donde estuvimos 15 días dando talleres. Luego salimos para otra Zona Veredal, en Colinas Guaviare, llamada Jaime Pardo Leal, donde también estuvimos 15 días compartiendo talleres. En ambas Zonas Veredales hicimos un mural realizado en colectivo con los excombatientes, donde ellos pudieron cambiar sus armas por pinceles y brochas (2017, p. 1).

En estos territorios, junto a excombatientes de la comunidad veredal y estudiantes de otras universidades, realizaron una serie de talleres de experimentación visual y crearon dos murales: el primero como una especie de memorial a un caído en combate, y el segundo con contenidos que le cantan al reconocimiento de la riqueza racial y natural.

Como resultado de los talleres colaborativos son el mural titulado "Urías Rondón” (2017), realizado por Mauricio Arcila, Anthony Ordoñez, la comunidad de excombatientes y estudiantes de las Universidades de Los Andes, Rosario, Javeriana y Nacional de Colombia, "que se encontraban allí, en ese momento y decidieron untarse un poco las manos".

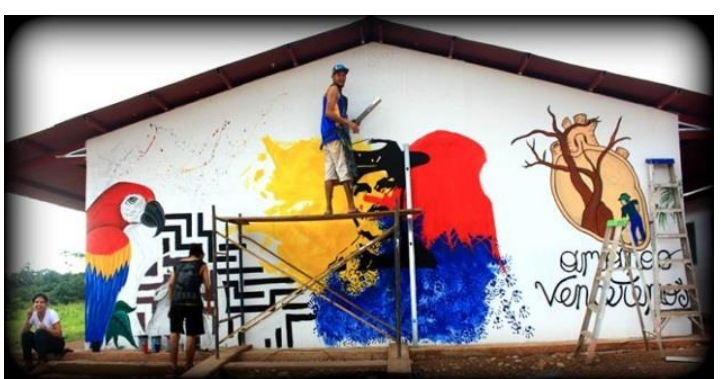

Figura 10 "Urías Rondón", Mural 7 m. X 4 m. Obra colectiva. Vinilos sobre concreto.

Lugar: Macarena, Meta, Zona Veredal del Yarí. 2017.

Fuente: Archivo fotográfico de Arlex Mauricio Arcila. 2017.

Como ya se mencionó, este primer mural se trata de un homenaje a Urías Rondón combatiente de las FARC, muerto en combate, de la Zona Veredal de la Macarena Meta. Por eso su silueta se encuentra en el centro de la composición; simultáneamente una especie de triángulo invertido, conformado por manchas irregulares del tricolor de la bandera, inunda la 
figura. La base del triángulo está integrada por grandes manchas de color amarillo y rojo, y tiene un tercer plano irregular de color azul, en el extremo inferior.

Al lado izquierdo aparece la figura de un papagayo, seguido por una especie de laberinto hecho con líneas rectas de color negro. En la parte derecha se encuentra la imagen de un corazón, que de su interior surge un tronco de un árbol sin hojas y en la parte inferior la imagen reducida de un campesino. Finalmente, la composición fue cubierta con improntas de diversos colores, hechas con las manos de las personas que contribuyeron para pintar el mural; quienes también escribieron en la parte superior y central el nombre del occiso.

El segundo mural titulado "Raíces" (2017) fue plasmado en la Zona Veredal Jaime Pardo Leal, en colinas Guaviare. Fue un segundo proyecto colaborativo realizado por Mauricio Arcila, excombatientes y estudiantes de la Universidad Industrial de Santander.

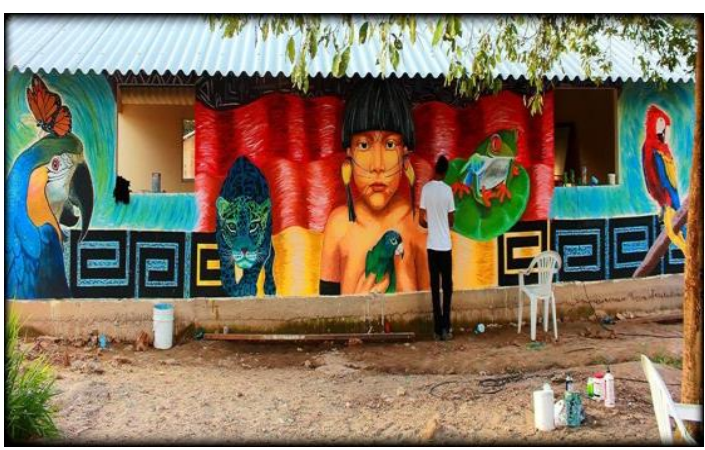

Figura 11 "Raíces". Mural 15 m. X 3 m. Obra colectiva. Vinilos sobre concreto.

Fuente: Archivo fotográfico de Arlex Mauricio Arcila. 2017.

Este segundo mural tiene evidentes relaciones con las raíces culturales y la naturaleza de los llanos orientales de Colombia. Lo primero se muestra en la parte inferior una especie de cenefa con formas de grecas continuas, que ocupa un poco menos de la tercera parte del muro, viéndolo en sentido horizontal: los tramos del extremo derecho e izquierdo de las figuras serpenteantes fueron pintadas con negro y se encuentran sobre fondos azules; mientras las del centro está sobre amarillo. Estas se transforman en la última franja de una especie de superficie ondulante del mismo color que se encuentra precedida de dos frisos ondeantes de tonalidades rojizas.

Del centro aparece el torso de un niño indígena, quien sostiene con su mano izquierda un loro. El rostro del niño posee una expresión serena mientras su mirada atenta parece interrogar a los espectadores. Al lado izquierdo del niño se encuentra 
El arte como posibilidad de mediación en los conflictos: escenarios, prácticas y visibilidad desde las experiencias en el Huila

un mítico jaguar en la penumbra, el cual parece avanzar con actitud amenazante; a la derecha del niño y en la mitad del muro una rana parece flotar sobre la hoja de una victoria regia.

Al lado derecho del mural se encuentra la cabeza de un enorme papagayo, que tiene en la parte superior una mariposa; en el otro extremo se halla la representación completa de un segundo papagayo. Las figuras de las aves fueron pintadas sobre grandes pinceladas concéntricas de tonos azules y verdes. Curiosamente, los papagayos, el loro y la rana parecen estar atentos de lo que acontece al lado derecho. Sobre la experiencia comenta el estudiante Arlex Mauricio Acila:

En todo el proceso de realización de los murales, me encontré con gente muy talentosa, en especial en este mural titulado raíces donde conocí a un joven de 25 años de edad, llamado Diomedes, también excombatiente; quien me aportó mucho a la realización del mural, y donde compartimos conocimientos; aún hoy en día le ayudo con su proceso de aprendizaje (2017, p. 1).

De otra parte, durante el pasado mes de octubre la profesora Rocío Polanía tuvo la oportunidad de orientar un taller de técnicas de escultura básica, a estudiantes de la Universidad de Guatemala. En este lugar se destacó por el impacto emocional que produjo, el hecho que un grupo de estudiantes pertenecientes a una etnia indígenas, basadas en experiencias vivenciales realizaron como ejercicios de representación una serie de modelados con el tema de la figura humana; sus figuraciones recalcan hechos traumáticos como sobrevivientes de la guerra interna guatemalteca.

$\begin{array}{rcc}\text { Las } & \text { "Formas } & \text { Modeladas" } \\ \text { (2017) } & \text { son } & \text { producciones }\end{array}$
resultantes del "Taller de escultura", orientado por la profesora Rocío Polanía Farfán en el marco del XXII Congreso Latinoamericano de Educación por el Arte convocado por el Consejo Latinoamericano de Educación por el Arte (CLEA). Las piezas son construcciones elaboradas en arcilla, que narran las huellas dejadas en la memoria por la Guerra contra el pueblo de Guatemala. Las obras están basadas en el testimonio vivencial de las prácticas terroríficas ejercidas sobre los parientes más cercanos. En las tres piezas secuencialmente son notables el fusilamiento de una familia, una violación en grupo, y el asesinato de una madre con la violenta extracción del hijo.

Según las estudiantes las tres acciones fueron ejecutadas por miembros de las fuerzas armadas guatemaltecas.

Como particularidad son similares a los hechos de barbarie, causados por 
el terrorismo implementado contra la población civil, como ha ocurrido en Colombia y Perú. Es como si el mismo patrón de barbarie se aplicara en distintos países, como una exitosa estrategia de guerra.

Estos ejercicios les permitieron a las estudiantes dar a conocer con detalles las tragedias familiares, al sustentar los contenidos de las piezas modeladas, como parte de los procesos de resiliencia en la que actualmente se encuentran; tal vez, con el fin que el dolor repercutido no termine de destruirlas.
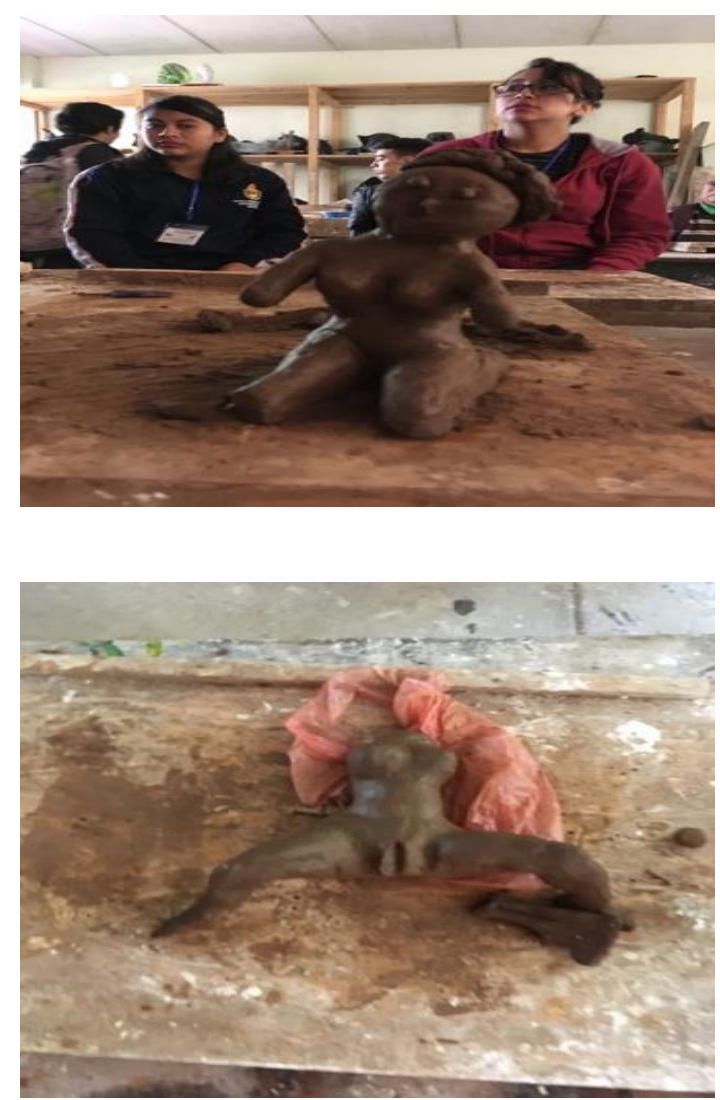

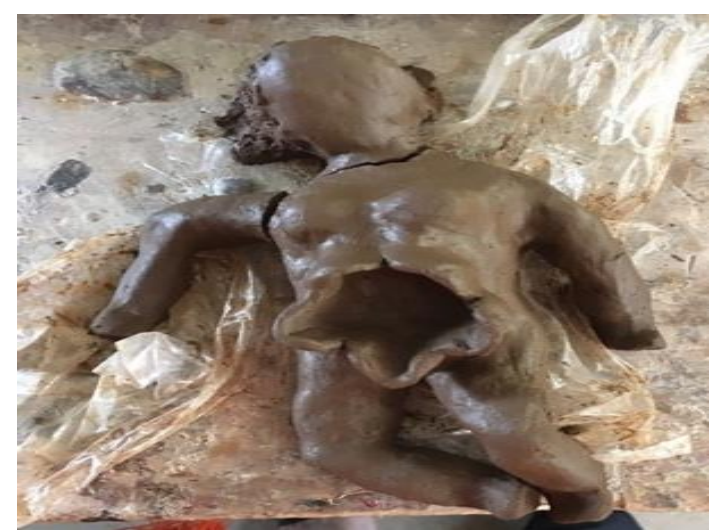

Figura 12 "Formas modeladas". Estudiantes Escuela Nacional de Artes Plásticas ENAP, Taller de escultura. XXII Congreso Latinoamericano de Educación por el Arte-CLEA. Guatemala. 2017.

Fuente: Archivo fotográfico de la Mg. Rocío Polanía Farfán.

\section{Conclusiones preliminares}

1. Podemos decir que la cuarta experiencia, de las explicadas en el último apartado y expuestas anteriormente, puede ser una Mediación como modelo educativo, en la medida que corresponde a prácticas formativas de la educación artística, implicando la experimentación y la expresión de vivencias profundas de las personas involucradas en el proceso.

Mientras la primera, segunda y tercera experiencias comentadas, se puede inscribir en la Mediación como campo de expansión, en el sentido que retoma las estrategias didácticas de la educación artística para formar los participantes, quienes finalmente 
El arte como posibilidad de mediación en los conflictos: escenarios, prácticas y visibilidad desde las experiencias en el Huila

contribuirán a la realización de los proyectos.

En este tipo de mediación se involucra una estrategia colaborativa; al tiempo que también se busca implicar otros campos disciplinares, como la psicología y la sociología en la búsqueda de fines comunes. En todas las experiencias de mediación se particulariza el potencial comunicativo que desatan las diversas actividades y las distintas formas de interrelación que pueden emerger; las cuales no pueden ser predecibles.

2. Respecto a las prácticas artísticas, las cuatro experiencias pueden corresponder al Arte Activista, ya que buscan trabajar con personas y colectivos invisibilizados. Además, poseen un claro enfoque Etnográfico, en el sentido que los proyectos planteados el accionar didácticocreativo se encamina a comunidades especificas; las cuales escenifican sus experiencias más profundas, convirtiéndose en auténticos protagonistas; mientras los artistas pasan a un segundo plano; y donde lo más apreciado es el proceso realizado, por encima de los resultados.

3. Son notorias las diferencias que existen entre la tercera y la cuarta experiencias. En la tercera son los supuestos perpetradores quienes de alguna manera también se exhiben como víctimas, en la medida que conmemoran a sus muertos $y$ anhelan una paz más equilibrada y justa. En la cuarta se reconstruye el accionar descarado de las fuerzas armadas guatemaltecas contra el pueblo inerme, como actos de barbarie excesivo.

4. En la primera y la segunda experiencia que abordamos, es apenas comprensible que no se puede soslayar en la mediación de las prácticas artísticas la presencia y encuentro de las víctimas y los perpetradores. Comprendida como una fase esencial de la conciliación, donde víctimas y perpetradores tienen la oportunidad de encontrarse para acordar la realización de propósitos comunes.

Para ello se ha promovido desde la legislación institucional los actos protocolarios de "solicitud de perdón" por parte de los victimarios, y la recomendación vicaria de "concesión de olvido" de las víctimas; escenificándose generalmente, como parte de un tinglado que oscila entre el simulacro impúdico de los primeros y la re-victimización de los segundos.

Es decir, como una performance vacía y desviada de los objetivos pretendidos, al convertirlos en un espectáculo falaz y sado-masoquista; donde se ofrece la memoria de la carne macerada y los cuerpos 
inexistentes para ser difunda por los medios; solamente como un indicativo propagandista de la eficiencia institucional reconciliadora.

Ya que "si la vida continúa y al continuar se ensancha, hay una superación de los factores de oposición y conflicto; hay una transformación de dichos factores en aspectos diferenciados de una vida más altamente poderosa y significativa" (Dewey, 2008, p. 16).

Tal vez como una respuesta a la situación anterior y con propósitos palpables se vienen gestando el acercamiento entre las víctimas y los perpetradores, con la mediación de las prácticas artísticas; haciendo posible la resiliencia y la estabilidad social que permite la continuidad de la mutua existencia.

5. Debido a los logros preliminares positivos y la trascendente acogida social, se deben sostener e incrementar en la medida que trascurre la reconciliación de los ciudadanos; pero, sobre todo, debido a que las comunidades participantes cobran relevancia, visibilidad y protagonismo. Por ello podemos decir, junto a Carnacea y Lozano (2011):

Así, la referencia a la acción social trae al sector social, un espacio de protagonismo nuevo en la sociedad; la referencia a la intervención trae el entendimiento actual de que podemos proponernos cambios en y desde los individuos y los colectivos; y la referencia al arte $\mathrm{y}$ al poder transformador de la creatividad pone en escena el papel de nuestras interpretaciones y el de la producción de lo simbólico como materia prima para despertar ese poder (p. 29).

6. Con lo anteriores experiencias podemos percibimos la urgencia de contribuir a la producción de cambios colectivos esenciales, generados desde la educación artística y las prácticas artísticas. Sin embargo, podemos recalcar que estas iniciativas se encuentran en la categoría de "gestación", por el carácter eminentemente experimental de la mediación artística en el conflicto.

7. En cuanto a las experiencias expuestas, a pesar de ser iniciativas acertadas, como todos los procesos de interacción social tan necesarios en nuestro país, luego que la violenta guerra, generan la necesidad de verificar los efectos producidos con el transcurrir del tiempo; debido a las dimensiones de riesgo éticas, estéticas, y políticas que se imbrican, objetivizan y ponen en escena.

\section{Referencias}

Arcila, Arlex Mauricio (2017). Comunicación escrita. Neiva: 
El arte como posibilidad de mediación en los conflictos: escenarios, prácticas y visibilidad desde las experiencias en el Huila

Documento de internet, octubre 2 de 2017.

Arcila, Arlex Mauricio (2017). Comunicación escrita. Neiva: Documento de internet, octubre 14 de 2017.

Carnacea, Ángeles y Lozano, Ana (Coords.) (2011). Arte, intervención y acción social. La creatividad transformadora. Madrid: Grupo 5.

Chalmers, F. Graeme (2003). Arte, educación y diversidad cultural. Barcelona: Paidós.

Dewey, John (2008). El arte como experiencia. Barcelona: Paidós.

El Tiempo (2017). "Memorias a color": un proyecto para la reconciliación. Bogotá, Febrero 15. Recuperado de http://www.eltiempo.com/politica /proceso-de-paz/proyectomemorias-a-color-60013

El Tiempo (2017). Víctimas $y$ victimarios se reunieron para "pintar" la paz. Bogotá, 18 de febrero. Recuperado de http://www.eltiempo.com/politica /proceso-de-paz/victimas-yvictimarios-se-reunieron-parapintar-la-paz-60452

Foster, Hal (2001). El retorno de lo real. La vanguardia a finales de siglo. Madrid: Akal.

González Calleja, Eduardo (2002). La violencia en la política. Perspectivas teóricas sobre el empleo deliberado de la fuerza en los conflictos de poder. Madrid: CSIC.
Guasch, Ana María (2007). El arte último del siglo XX. Del posminimalismo a lo multicultural. Madrid: Alianza.

Lacy, Suzanne (1994). Debated territory. Toward critical language for public art. In Mapping the terrain. New Genre Public Art. Recuperado de https://www.uniarts.fi/sites/defau lt/files/Lacydebated\%20territory.pdf. Consultada septiembre 4 de 2017.

La Nación (2014). "Paraíso tiene mil colores". Neiva, 29 de mayo. Recuperado de http://www.lanacion.com.co/2014 /05/29/paraiso-tiene-mil-colores/ Consultada octubre 16 de 2017.

Mbembe, Achille (2011). Necropolítica. Seguido sobre el gobierno privado indirecto. Santa Cruz de Tenerife: Melusina.

Pilan, Hânia Cecília (2010). Arte, uma necessidade vital. En Revista Trama interdisciplinar Vol.1, N 2. Sao Paulo: Universidade Presbiteriana Mackenzie, pág. 154$160 . \quad$ Recuperado de http://editorarevistas.mackenzie.b r/index.php/tint/article/view/312 $0 / 2623$. Consultada septiembre 2 de 2017.

Rodrigo-Montero, Javier (2015). Kunstcoop: Experiencias de mediación artística en Alemania. En Revista Arte, Individuo y Sociedad Vol. 27, N 3. Madrid: Complutense, pág. 375-393. Recuperado de https://revistas.ucm.es/index.php/ ARIS/article/viewFile/43723/4640 
5. Consultada septiembre 3 de 2017.

Ruiz Solórzano, Jaime (2017). Conferencia "Imágenes inhibidas: cuatro respuestas". Neiva: Universidad Surcolombiana (inédito).

Vásquez Rocca, Adolfo (2016). Sloterdijk: posdemocracia impositiva y genealogía del orgullo (thymos). En Revista Trama interdisciplinar Vol.7, N 3. Sao Paulo: Universidade Presbiteriana Mackenzie, pág. 201-218. Disponible en http://editorarevistas.mackenzie.b r/index.php/tint/article/view/935 $3 / 6302$. Consultada septiembre 2 de 2017.

Wills Otero, Laura y Martínez-Villalba, Camila (2003). La mediación como herramienta para la resolución de conflictos armados internos. Bogotá: Alfaomega colombiana. 